\title{
Coordination cages transport molecular cargoes across liquid membranes
}

Bao-Nguyen T. Nguyen ${ }^{1}$, John D. Thoburn ${ }^{2}$, Angela B. Grommet ${ }^{1}$, Duncan Howe ${ }^{1}$, Tanya K. Ronson $^{1}$, Hugh P. Ryan ${ }^{1}$, Jeanne L. Bolliger ${ }^{1}$, Jonathan R. Nitschke ${ }^{1 *}$

${ }^{1}$ University of Cambridge, Department of Chemistry, Cambridge CB2 1EW, UK.

${ }^{2}$ Randolph-Macon College, Department of Chemistry, Ashland, VA, 23005, USA.

*Correspondence to: jrn34@cam.ac.uk.

Chemical purifications are critical processes across many industries, requiring 10 - 15\% of humanity's global energy budget ${ }^{1,2}$. Coordination cages are able to catch and release guest molecules based upon their size and shape ${ }^{3,4}$, providing a new technological basis for achieving chemical separation. Here we show that aqueous solutions of $\mathrm{Fe}^{\mathrm{II}_{4}} \mathrm{~L}_{6}$ and $\mathrm{Co}{ }_{4} \mathrm{~L}_{4}$ cages can be used as liquid membranes. Selective transport of complex hydrocarbons across these membranes enabled the separation of target compounds from mixtures under ambient conditions. The kinetics of cage-mediated cargo transport are governed by guest binding affinity. Using sequential transport across two consecutive membranes, target compounds were isolated from a mixture in a size-selective fashion. The selectivities of both cages thus enabled a two-stage separation process to isolate a single compound from a mixture of physicochemically similar molecules.

The binding properties of coordination cages in solution ${ }^{5-17}$ has been tailored to species ranging from gases ${ }^{18-21}$ to heavy metals ${ }^{21}$, and neutral ${ }^{22-24}$ and charged compounds ${ }^{25-30}$. A cage dissolved in one fluid phase is capable of extracting a guest from another immiscible one, without crossing the phase barrier ${ }^{31}$. We envisaged that a cage dissolved in a water layer sandwiched between two organic solvent layers might be able to shuttle guests from one organic phase to the other. The aqueous cage layer would thus serve as a liquid membrane between the organic phases, with its guest-binding selectivity governing which molecules undergo transit.

The threat of global warming lends urgency to the goal of purifying chemical mixtures at a lower energy cost than is currently possible. Distillation to refine petroleum, as an example of an economically essential bulk process, requires burning a portion of the input to generate the thermal energy needed for separation. Membrane separation methods promise better efficiency. 
Chemical separation using bulk liquid membranes ${ }^{32-34}$ has been seen as a promising prospect for many years. Such membranes consist of a fluid phase that is not miscible with two other liquids, and which separates them. They have been demonstrated to separate ions ${ }^{34}$ and heavy metals ${ }^{35-38}$, but not neutral molecules as yet.

Here we introduce the use of coordination cages as active carriers ${ }^{39,40}$ within liquid membranes. By selectively transporting neutral molecule guests across an aqueous layer, cages separate compounds from a mixture according to their binding affinity. As shown in Fig. 1a, our system consists of a cage in an aqueous phase which acts as a membrane separating two organic layers, the feedstock and receiving phases. The feedstock contains a solution of prospective guest compounds, while the receiving phase consists of neat organic solvent. Cages within the liquid membrane selectively encapsulate target guest molecules at the feedstock phase boundary, transport them across the membrane, and release them into the receiving phase. This system is driven spontaneously towards equilibrium at ambient temperature, demonstrating how chemicals can be purified and highlighting a potential alternative to thermal separation methods.

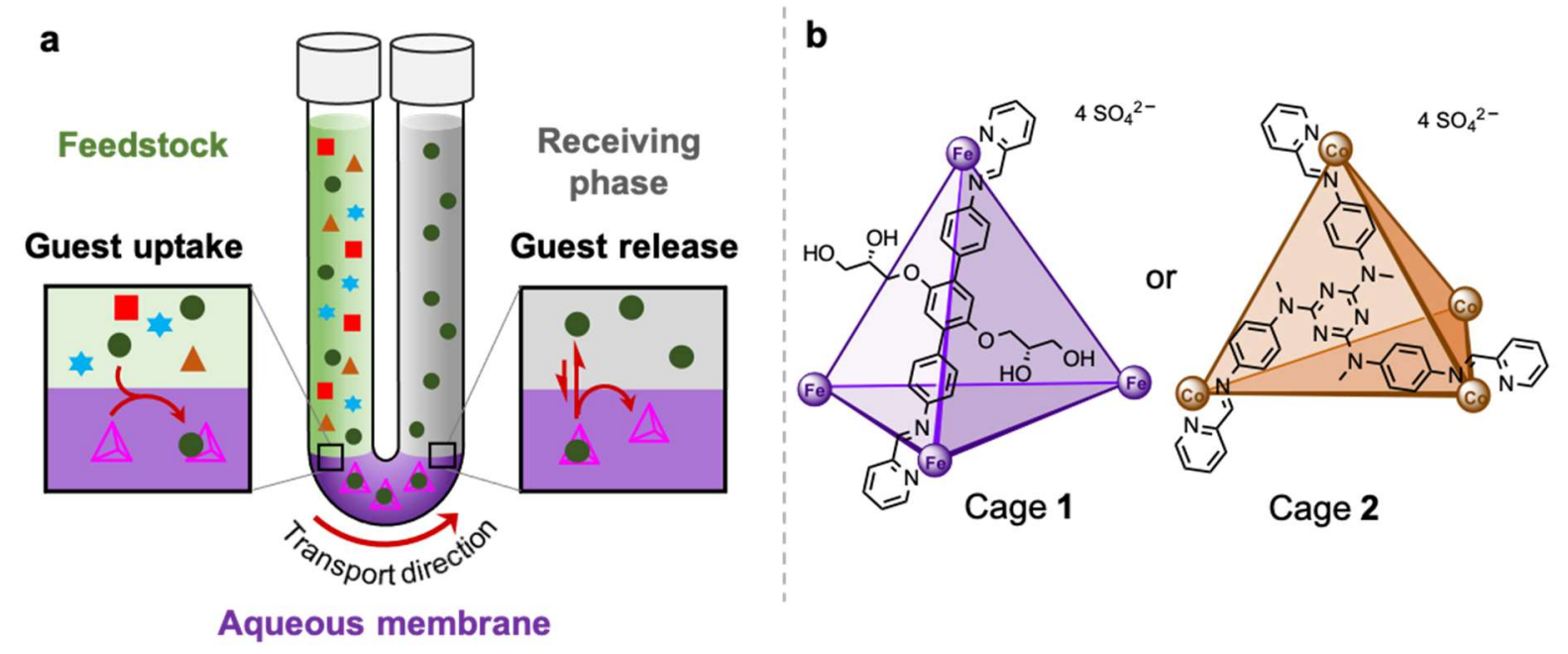

Fig. 1 a, Illustration of the triphasic system setup in the U-shape tube and schematic mechanism of naphthalene transport by cages. Naphthalene $(\bullet)$ is encapsulated at the boundary between feedstock and aqueous membrane layers. The cages and their encapsulated cargoes diffuse through the aqueous layer to the receiving phase boundary. The encapsulated cargoes then released from the cage cavities into the receiving organic phase. $\mathbf{b}$, Cages chosen for the aqueous membranes. 
Kinetic studies of naphthalene transport through liquid membranes of cage 1 and 2. Sulfate salts of tetrahedral $\mathrm{Fe}^{\mathrm{II}} \mathrm{L}_{6}$ cage $\mathbf{1}^{41}$ and $\mathrm{Co}_{4}{ }_{4} \mathrm{~L}_{4}$ cage $\mathbf{2}^{4}$ (Fig. 1b) were prepared and dissolved in water. The aqueous solutions of $\mathbf{1}$ and $\mathbf{2}$ were loaded into the bottom of U-shaped tubes (Fig. 1a). Feedstock solutions containing naphthalene dissolved in dodecane were then loaded into the stock arm, while pure dodecane was introduced to the receiving arm as the receiving phase (Fig. S8). Naphthalene was chosen as a guest molecule for these experiments because it was observed to bind strongly to both cage 1 (Fig. S24) and 2 in water ${ }^{41}$. Dodecane was chosen as the solvent because it readily dissolves naphthalene and has a boiling point of $216^{\circ} \mathrm{C}$, thus minimizing solvent loss due to evaporation.

Both cages 1 and $\mathbf{2}$ were observed to transport naphthalene across the aqueous membrane, with cage 1 (Fig. 2a) transferring naphthalene more rapidly than cage $\mathbf{2}$ (Fig. 2b). The transport data shown in Fig. 2 were fitted to a three-state model, in which the naphthalene is distributed between the feedstock $\operatorname{arm}\left(\mathrm{N}_{\mathrm{A}}\right)$, the in-cage encapsulated state $\left(\mathrm{N}_{\mathrm{B}}\right)$ in the aqueous membrane, and the receiving arm $\left(\mathrm{N}_{\mathrm{C}}\right)$. The data for $\mathrm{N}_{\mathrm{A}}$ and $\mathrm{N}_{\mathrm{C}}$ were fit simultaneously using a nonlinear least-squares fit as implemented on Mathematica (Supporting Information, Section 5.2). The concentration of cage-encapsulated naphthalene, $\mathrm{N}_{\mathrm{B}}$, was not measured, but rather determined from mass balance based on the fitted intensities for $\mathrm{N}_{\mathrm{A}}$ and $\mathrm{N}_{\mathrm{C}}$.

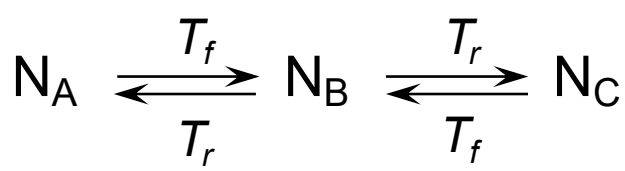

The fitting results (Fig. 2) suggested that the time required to obtained $50 \%$ of the naphthalene amount to be transferred to the receiving arm is 2.0 days for cage $\mathbf{1}$ and 9.4 days for cage 2 (Table S3). We attribute the faster transport of naphthalene by cage 1 to more rapid guest ingress and egress from the cage framework, in which the passable apertures are opened and closed by hydrogen bonds between the flexible glycerol chains. In contrast, the more enclosed framework of cage 2 presents a higher energetic barrier to guest uptake and release. Indeed, cage 1 was observed to encapsulate naphthalene in fast exchange on the ${ }^{1} \mathrm{H}$ NMR timescale, whereas cage 2 was observed to bind naphthalene in slow exchange (Fig. S24).

Fitting to our model produced the rate constants given in Table S2, which are conveniently expressed in terms of molar fluxes $J_{f}$ and $J_{r}$ according to the equations $J_{f}=T_{f}[N] \cdot[$ cage $]$ and $J_{r}=T_{r}[N \cdot$ cage $]$, where $T_{f}$ and $T_{r}$ are the forward and reverse transport constants. For ingress into the aqueous cage 1 layer, $T_{f}^{1}=0.157 \pm 0.003 \mathrm{mM}^{-1} \cdot \mathrm{day}^{-1} \cdot \mathrm{cm}^{-2}$, and for egress back into 
dodecane $T_{r}^{1}=12 \pm 5 \mathrm{day}^{-1} \cdot \mathrm{cm}^{-2}$. Naphthalene transport through the aqueous membrane containing cage 2 was fitted to the same equations, resulting in molar flux transport constants $T_{f}^{2}=0.045 \pm 0.001 \mathrm{mM}^{-1} \cdot \mathrm{day}^{-1} \cdot \mathrm{cm}^{-2}$ and $T_{r}^{2}=0.14 \pm 0.01 \mathrm{day}^{-1} \cdot \mathrm{cm}^{-2}$ for ingress and egress, respectively.
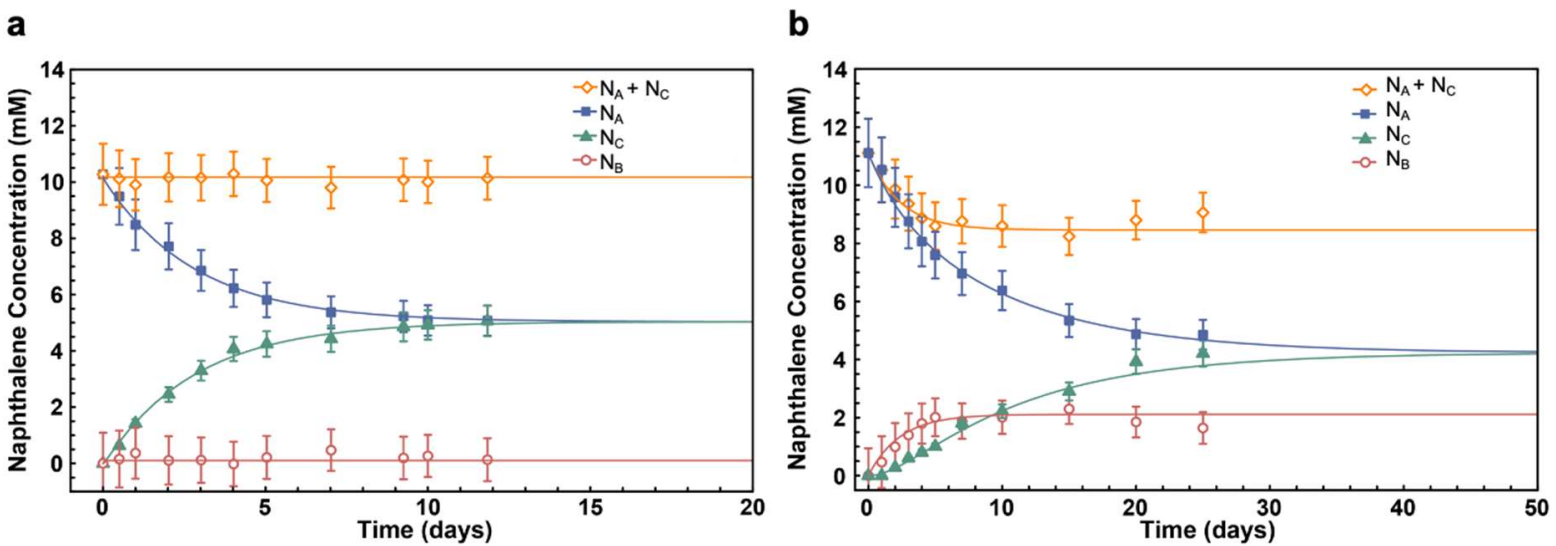

Fig. 2 The transport of naphthalene mediated by a, cage $\mathbf{1}$ and $\mathbf{b}$, cage $\mathbf{2}$ from the feedstock to the receiving phase. Fitting to the transport model described in Supporting Information Section 5.2 provided molar flux values for guest transport through the aqueous membrane. $\left(\mathrm{N}_{\mathrm{A}}\right.$ $=$ The naphthalene concentration distributed in the feedstock arm, $\mathrm{N}_{\mathrm{B}}=$ in the cage layer, $\mathrm{N}_{\mathrm{C}}=$ in the receiving arm).

The sigmoidal rise in concentration of naphthalene in the receiving arm when cage $\mathbf{2}$ is the carrier (Fig. 2b) indicates an induction period, during which time the host-guest intermediate builds up in the aqueous membrane, limiting the transfer rate. Such an induction period was observed in the case of the smaller $T_{f}\left(0.045 \mathrm{mM}^{-1} \cdot \mathrm{day}^{-1} \cdot \mathrm{cm}^{-2}\right)$ for cage 2 , but not in the case of the larger $T_{f}\left(0.157 \mathrm{mM}^{-1} \cdot \mathrm{day}^{-1} \cdot \mathrm{cm}^{-2}\right)$ for cage $\mathbf{1}$.

Our kinetic data showed that the molar flux for guest egress was greater than for guest ingress $\left(T_{r}>T_{f}\right)$, consistent with our observation that naphthalene release to the dodecane layers is more favorable than binding to the cages. The cage in the aqueous membrane must compete effectively with the dodecane solvent for naphthalene at the stock solution/aqueous phase boundary, yet still allow the release of naphthalene across the phase boundary into the receiving phase. Cage 1 was observed to be more effective than cage $\mathbf{2}$ at transporting naphthalene because it more readily took up $\left(T_{f}^{1}>T_{f}^{2}\right)$ and released guests $\left(T_{r}^{1}>T_{r}^{2}\right)$, reflecting the structural differences between the two cages discussed above.

To further investigate the role of the two cages in transporting naphthalene from the stock to the receiving arms, a control experiment was conducted. In place of the cage solution, 
deionized water was loaded into the bottom of a U-shaped tube, separating a feedstock solution containing naphthalene in dodecane from a receiving phase of pure dodecane. In the absence of cage carriers, naphthalene was observed to diffuse across the liquid membrane at a much slower rate (Fig. S20) with $T_{f}=0.0049 \pm 0.0004 \mathrm{mM}^{-1} \cdot \mathrm{day}^{-1} \cdot \mathrm{cm}^{-2}$ and $T_{r}=0.14 \pm 0.01$ day $^{-}$ ${ }^{1} \cdot \mathrm{cm}^{-2}$.

Although the transport coefficients for these processes are small, the underlying physics allows the rate to be increased by simple modifications. For example, quadrupling the tube radius from $r=0.6 \mathrm{~mm}$ to $2.4 \mathrm{~mm}$ would increase the cross-sectional area and thus the flux by a factor of 16. This modification would reduce the naphthalene transport time without any change in the underlying functioning of the system. Additional rate enhancements can be achieved by increasing the amount of cage, as illustrated in Fig. S21a.

Selective guest filtering by sequential setup of cage 1 and 2 membranes. Having investigated the active transport of naphthalene across aqueous cage membranes, we began to explore systems wherein a series of cages selectively separated guests from a mixture. Because cages 1 and $\mathbf{2}$ have different internal volumes, we anticipated that they would transport different subsets of guest molecules. A feedstock of naphthalene, mesitylene, cis-stilbene, and triisopropylbenzene was thus chosen to demonstrate separation using coordination cage membranes. These molecules have different shapes and sizes, and were therefore expected to bind to cages 1 and $\mathbf{2}$ with different affinities and kinetics. Taking advantage of these differences, we anticipated that the compounds would be selectively transported through the aqueous membranes by the two coordination cage carriers.

We thus designed a system comprising two stages. The first stage contained the larger cage 1 within the aqueous membrane, which allowed the transport of a set of larger guests. The second stage contained the smaller cage $\mathbf{2}$, which bound smaller guests than cage $\mathbf{1}$.

In the first stage, after 43 days approximately $50 \%$ of the naphthalene had been transported by cage 1, resulting in $15 \mathrm{mM}$ of the compound in both arms. Furthermore, mesitylene $(6.3 \mathrm{mM}$, $21 \%)$ and cis-stilbene $(4.7 \mathrm{mM}, 16 \%)$ were transported into the receiving arm. No triisopropylbenzene was observed to undergo transport.

Naphthalene was observed to transport most rapidly compared to the other three guests and mesitylene transported faster than cis-stilbene. We attribute the differences in guest transport rates to an interplay of kinetics and thermodynamics of guest binding. Naphthalene and mesitylene exited and entered 1 rapidly on the ${ }^{1} \mathrm{H}$ NMR timescale, whereas the exchange of 
cis-stilbene and triisopropylbenzene was slow by NMR. Naphthalene and mesitylene thus kinetically outcompeted cis-stilbene to bind within $\mathbf{1}$.

To probe the relative binding affinities of the guests for cage $\mathbf{1}$ in water, we carried out a guestdisplacement assay. The following guests were added to cage 1 in water $(1 \mathrm{mM}, 0.5 \mathrm{~mL})$ : first triisopropylbenzene, then cis-stilbene, next mesitylene, and finally naphthalene. After the addition of each guest, the sample was analyzed by ${ }^{1} \mathrm{H}$ NMR, to verify the progressive displacement of the encapsulated guests (Supporting information Section 9.2, Fig. S25).

The relative guest binding affinities thus help to account for the outcomes when multiple guests compete to transport. Due to its stronger guest binding affinity, naphthalene outcompeted mesitylene to bind within 1, and was thus transported preferentially. Cis-stilbene was transported next because it bound to cage 1 more strongly in turn than triisopropylbenzene. Triisopropylbenzene bound only weakly to cage 1, and was not extracted from the stock layer by cage 1 . The transport of triisopropylbenzene was, therefore, not observed.
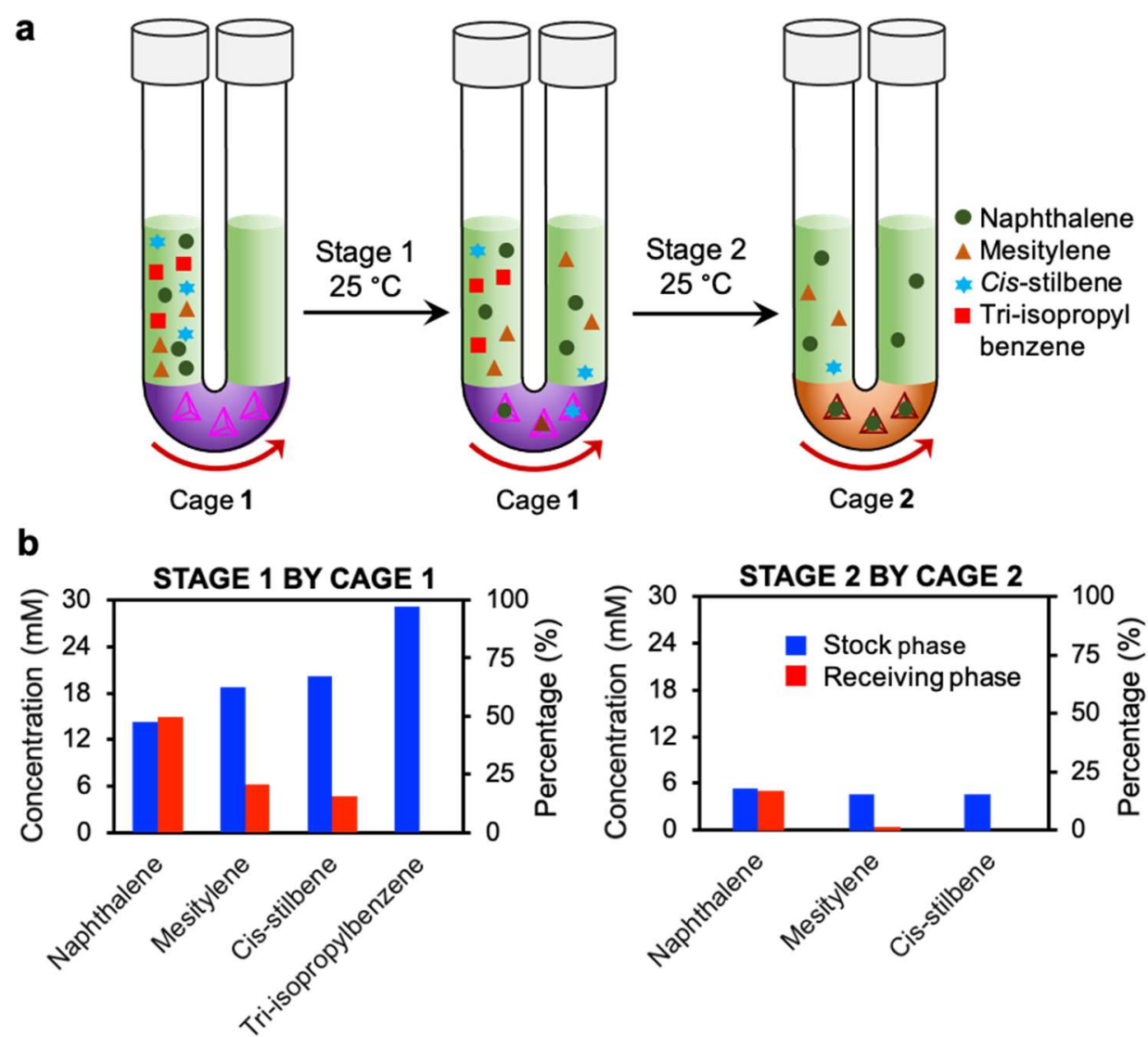

Fig. 3 | Illustration of the stepwise chemical separation. a, A mixture of naphthalene, mesitylene, cis-stilbene and triisopropylbenzene was initially introduced to the feedstock arm of the first tube. Cage 1 selectively filtered naphthalene, mesitylene and cis-stilbene to the 
receiving arm, which then became the feedstock arm of the second stage, wherein cage 2 subsequently separated naphthalene from mesitylene and cis-stilbene. b, Plots showing distribution of the compounds in the receiving phases following separation by cages $\mathbf{1}$ and 2 . To evaluate the diffusion effect on stage 2 guest transport, a control experiment was set up with water replacing the cage 2 solution. After an identical experiment duration of 25 days, only 1.3 $\mathrm{mM}$ of naphthalene, equivalent to $4 \%$ of the total, and $0.2 \mathrm{mM}$ of mesitylene, equivalent to $0.7 \%$ of the total, were observed in the receiving arm. Cis-stilbene was not observed to transit.

In stage 2 of the sequential guest purification system, the receiving phase from stage 1 containing naphthalene, mesitylene and cis-stilbene was transferred into the feedstock arm of a new U-tube. An aqueous solution of cage 2 was added as the second membrane and a new dodecane receiving layer was introduced (Fig. 3a, S23). After 25 days, naphthalene had equilibrated across both arms, and mesitylene $(0.3 \mathrm{mM}, 1 \%)$ was also observed in the receiving arm, whereas no cis-stilbene was observed to transit.

Guests with stronger binding affinities impeded the transport of the weaker binding ones. To gauge competition between the guest compounds in the stock mixture, four control experiments were carried out, with either naphthalene, mesitylene, cis-stilbene or triisopropylbenzene (30 $\mathrm{mM}$ each) present in the stock phase in the absence of the others. The experiments were analogous to the stage 1 separation using cage 1 . The guest transport to the receiving arms was monitored by ${ }^{1} \mathrm{H}$ NMR for the first 7 days and after 43 days, the duration of stage 1 separation. In the absence of competing guests, a higher amount of mesitylene $(7.1 \mathrm{mM}, 24 \%)$ and cisstilbene $(8.2 \mathrm{mM}, 27 \%)$ were independently transported to the receiving arms. Triisopropylbenzene was not transported even in the absence of other guests. Notably, while more mesitylene than cis-stilbene was transported in stage 1, cis-stilbene showed a faster independent transport in the control experiment, suggesting that the transport of cis-stilbene was improved in the absence of the other competing guests. (Supporting information, Fig. S29) Our results highlight the competing effects between the guests for the cage cavities and suggest that guests with stronger binding affinities could impede the transport of those with weaker binding strengths.

In summary, we demonstrated the use of metal-organic cages as the active carriers in a new class of liquid membranes. Many more cages are available than the two studied herein, with varying shapes, sizes, and guest affinities, allowing our strategy to be broadly applied to many 
separation challenges. Many different solvents can also be used for these cages, including ionic liquids $^{42}$, potentially removing problems of membrane-phase evaporation and enabling membranes to be constructed to preclude transit outside of cage carriers. Increasing interface area and decreasing the transit distance will also increase rates of mass flow through these membranes. Following these optimizations, the strategy outlined here may be developed into a practical means of low-energy, high-fidelity chemical separation in industry, as is required for the inevitable shift away from using hydrocarbons as fuels, and towards using them to construct new materials.

\section{Methods:}

Cage 1 and 2 were synthesised following reported procedures ${ }^{4,41}$.

Kinetics experimental setup. An aqueous solution of either cage 1 or cage $2(2 \mathrm{mM}, 2.5 \mathrm{~mL})$ was employed as a membrane layer, separating a feedstock arm and a receiving arm. The receiving arm contained a neat dodecane solution with coronene $(0.25 \mathrm{mM})$ standard. The feedstock arm contained a naphthalene solution $(10 \mathrm{mM}, 2 \mathrm{~mL})$ in dodecane. Knowing for unbinding to the cages and insoluble in water, coronene $(0.25 \mathrm{mM})$ and tetraphenylbenzene $(0.5 \mathrm{mM})$ were introduced as the ${ }^{1} \mathrm{H}$ NMR concentration standard and an indicator for the experiment. The experiment was stirring with a magnetic bar at a constant speed of $250 \mathrm{rpm}$, which was observed to avoid disturbance to the solutions in the two arms (Supporting Information, Section 5.1).

As dodecane has been reported to bind to cage 1 in fast exchange, this solvent could potentially compete with and displace encapsulated naphthalene. To investigate if dodecane was transported by the cages in the triphasic system, 1-fluorododecane $(10 \mathrm{mM})$ was introduced to the receiving arm. The transport of 1-fluorododecane from the receiving to the feedstock arm would be quantified by referencing to octafluoro-9,10-bis[4-(trifluoromethyl)phenyl]anthracene, a ${ }^{19} \mathrm{~F}$ NMR concentration standard, present in both arms. The 1-fluorododecane concentration in the two arms were monitored by ${ }^{19} \mathrm{~F}$ NMR.

Experimental setup for selective guest filtering experiments. Stage 1 filtration took place with cage $1(2.0 \mathrm{mM}, 2.5 \mathrm{~mL})$ solution. A feedstock solution containing naphthalene, mesitylene, cis-stilbene and tri-isopropyl benzene $(30 \mathrm{mM}$ each, $2 \mathrm{~mL})$ in dodecane was added to the feedstock arm. Tetraphenylbenzene was added as an indicator for the experiment. 
Dodecane $(2 \mathrm{~mL})$ was used as the receiving phase. The transport of the four guests was monitored in both arms by ${ }^{1} \mathrm{H}$ NMR, referencing to coronene $(0.25 \mathrm{mM})$ (Fig. S22).

Stage 2 filtration was caried out with cage $2(2.0 \mathrm{mM}, 2.5 \mathrm{~mL})$ solution. In a separate U-tube, the solution $(1 \mathrm{~mL})$ extracted from the receiving arm in stage 1 was added as a new feedstock phase. The layer contained naphthalene $(15 \mathrm{mM})$, mesitylene $(6.3 \mathrm{mM})$ and cis-stilbene $(4.7$ $\mathrm{mM})$. Tetraphenylethylene $(0.5 \mathrm{mM})$ was added as an indicator. A new dodecane solution (1 $\mathrm{mL}$ ) containing coronene $(0.25 \mathrm{mM})$ was added as a new receiving phase to collect guests transported by cage 2 (Fig. S23).

\section{References and Notes:}

1. Sholl, D. S. \& Lively, R. P. Seven chemical separations to change the world. Nature 532, 435-437 (2016).

2. Oak Ridge National Loboratory. Materials for separation technologies: energy and emission reduction opportunities. (2005).

3. Turega, S. et al. Shape-, size-, and functional group-selective binding of small organic guests in a paramagnetic coordination cage. Inorg. Chem. 52, 1122-1132 (2013).

4. Bolliger, J. L., Ronson, T. K., Ogawa, M. \& Nitschke, J. R. Solvent effects upon guest binding and dynamics of a Fe ${ }_{4}{ }_{4} \mathrm{~L}_{4}$ cage. J. Am. Chem. Soc. 136, 14545-14553 (2014).

5. Stang, P. J. Molecular architecture: Coordination as the motif in the rational design and assembly of discrete supramolecular species - Self-assembly of metallacyclic polygons and polyhedra. Chem. Eur. J. 4, 19-27 (1998).

6. Leininger, S., Olenyuk, B. \& Stang, P. J. Self-Assembly of Discrete Cyclic Nanostructures Mediated by Transition Metals. Chem. Rev. 100, 853-907 (2000).

7. Fujita, M. Metal-directed self-assembly of two- and three-dimensional synthetic receptors. Chem. Soc. Rev. 27, 417-425 (1998).

8. Fujita, D. et al. Self-assembly of tetravalent Goldberg polyhedra from 144 small components. Nature 540, 563-566 (2016).

9. Pan, M., Wu, K., Zhang, J. H. \& Su, C. Y. Chiral metal-organic cages/containers (MOCs): From structural and stereochemical design to applications. Coord. Chem. Rev. 378, 333-349 (2019).

10. Hong, C. M., Kaphan, D. M., Bergman, R. G., Raymond, K. N. \& Toste, F. D. Conformational Selection as the Mechanism of Guest Binding in a Flexible Supramolecular Host. J. Am. Chem. Soc. 139, 8013-8021 (2017).

11. Whitehead, M., Turega, S., Stephenson, A., Hunter, C. A. \& Ward, M. D. Quantification of solvent effects on molecular recognition in polyhedral coordination cage hosts. Chem. Sci. 4, 2744-2751 (2013).

12. Bloch, W. M. et al. Geometric complementarity in assembly and guest recognition of a bent heteroleptic cis- $\left[\mathrm{Pd}_{2} \mathrm{~L}_{2}{ }_{2} \mathrm{~L}_{2}{ }_{2}\right]$ coordination cage. J. Am. Chem. Soc. 138, 1375013755 (2016). 
13. Liu, Y., Hu, C., Comotti, A. \& Ward, M. D. Supramolecular Archimedean Cages Assembled with 72 Hydrogen Bonds. Science 333, 436-440 (2011).

14. Yoshizawa, M., Tamura, M. \& Fujita, M. Diels-Alder in Aqueous Molecular. Science 312, 251-255 (2006).

15. Li, X.-Z. et al. A supramolecular lanthanide separation approach based on multivalent cooperative enhancement of metal ion selectivity. Nat. Commun. 9, 547 (2017).

16. Johnson, A. M. et al. Narcissistic self-sorting in self-assembled cages of rare earth metals and rigid ligands. Angew. Chem. Int. Ed. 54, 5641-5645 (2015).

17. Akine, S. \& Sakata, Y. Control of guest binding kinetics in macrocycles and molecular cages. Chem. Lett. 49, 428-441 (2020).

18. Pei, W. Y. et al. A calix[4]resorcinarene-based giant coordination cage: controlled assembly and iodine uptake. Chem. Commun. 56, 2491-2494 (2020).

19. Zhang, X. et al. Fine-tuning apertures of metal-organic cages: Encapsulation of carbon dioxide in solution and solid state. J. Am. Chem. Soc. 141, 11621-11627 (2019).

20. Zhang, D. et al. Enantiopure $\left[\mathrm{Cs}^{+} / \mathrm{Xe} \subset \mathrm{Cryptophane}\right] \subset \mathrm{Fe}^{\mathrm{II}}{ }_{4} \mathrm{~L}_{4}$ hierarchical superstructures. J. Am. Chem. Soc 141, 8339-8345 (2019).

21. Roukala, J. et al. Encapsulation of xenon by a self-assembled $\mathrm{Fe}_{4} \mathrm{~L}_{6}$ metallosupramolecular cage. J. Am. Chem. Soc. 137, 2464-2467 (2015).

22. Gou, X. X., Peng, J. X., Das, R., Wang, Y. Y. \& Han, Y. F. On/off fluorescence emission induced by encapsulation, exchange and reversible encapsulation of a BODIPY-guest in self-assembled organometallic cages. Dalt. Trans. 48, 7236-7241 (2019).

23. Djemili, R. et al. Positive allosteric control of guests encapsulation by metal binding to covalent porphyrin cages. Chem. Eur. J. 25, 1481-1487 (2019).

24. Fuertes-Espinosa, C. et al. Purification of uranium-based endohedral metallofullerenes (EMFs) by selective supramolecular encapsulation and release. Angew. Chem. Int. Ed. 57, 11294-11299 (2018).

25. Lu, Z., Ronson, T. K. \& Nitschke, J. R. Reversible reduction drives anion ejection and C60 binding within an $\mathrm{Fe}^{\mathrm{II}}{ }_{4} \mathrm{~L}_{6}$ cage. Chem. Sci. 11, 1097-1101 (2020).

26. Bourgeois, J. P., Fujita, M., Kawano, M., Sakamoto, S. \& Yamaguchi, K. A cationic guest in a $24^{+}$cationic host. J. Am. Chem. Soc. 125, 9260-9261 (2003).

27. Bruns, C. J. et al. Emergent ion-gated binding of cationic host-guest complexes within cationic $\mathrm{M}_{12} \mathrm{~L}_{24}$ molecular flasks. J. Am. Chem. Soc. 136, 12027-12034 (2014).

28. Ogata, D. \& Yuasa, J. Dynamic open coordination cage from nonsymmetrical imidazole-pyridine ditopic ligands for turn-on/off anion binding. Angew. Chem. Int. Ed. 131, 18595-18599 (2019).

29. Lee, J., Lim, S., Kim, D., Jung, O. S. \& Lee, Y. A. Flexibility and anion exchange of $\left[(\mathrm{X}) @ \mathrm{Pd}_{2} \mathrm{~L}_{4}\right]$ cages for recognition of size and charge of polyatomic anions. Dalt. Trans. 49, 15002-15008 (2020).

30. Davis, A. V. et al. Guest exchange dynamics in an $\mathrm{M}_{4} \mathrm{~L}_{6}$ tetrahedral host. J. Am. Chem. Soc. 128, 1324-1333 (2006).

31. Zhang, D., Ronson, T. K., Mosquera, J., Martinez, A. \& Nitschke, J. R. Selective anion 
extraction and recovery using a $\mathrm{Fe}^{\mathrm{II}}{ }_{4} \mathrm{~L}_{4}$ cage. Angew. Chem. Int. Ed. 130, 3779-3783 (2018).

32. Nabieyan, B., Kargari, A., Kaghazchi, T., Mahmoudian, A. \& Soleimani, M. Benchscale pertraction of iodine using a bulk liquid membrane system. Desalination 214, 167-176 (2007).

33. Mohammed, A. A., Hussein, M. A. \& Albdiri, A. D. Z. Application of bulk liquid membrane technique for cadmium extraction from aqueous solution. Arab. J. Sci. Eng. 43, 5851-5858 (2018).

34. Qin, L. et al. Extraction and transport of sulfate using macrocyclic squaramide receptors. Chem. Sci. 11, 201-207 (2020).

35. Dalali, N., Yavarizadeh, H. \& Agrawal, Y. K. Separation of zinc and cadmium from nickel and cobalt by facilitated transport through bulk liquid membrane using trioctyl methyl ammonium chloride as carrier. J. Ind. Eng. Chem. 18, 1001-1005 (2012).

36. Safavi, A. \& Shams, E. Selective and efficient transport of $\mathrm{Hg}(\mathrm{II})$ through bulk liquid membrane using methyl red as carrier. J. Memb. Sci. 144, 37-43 (1998).

37. Zhang, W. et al. Kinetic study of chromium(VI) facilitated transport through a bulk liquid membrane using tri-n-butyl phosphate as carrier. Chem. Eng. J. 150, 83-89 (2009).

38. Korkmaz Alpoguz, H., Memon, S., Ersoz, M. \& Yilmaz, M. Transport of $\mathrm{Hg}^{2+}$ through bulk liquid membrane using a bis-calix[4] arene nitrile derivative as carrier: Kinetic analysis. New J. Chem. 26, 477-480 (2002).

39. Reusch, C. F. \& Cussler, E. L. Selective membrane transport. AIChE J. 19, 736-741 (1973).

40. Oshima, T., Inoue, K., Furusaki, S. \& Goto, M. Liquid membrane transport of amino acids by a calix[6]arene carboxylic acid derivative. J. Memb. Sci. 217, 87-97 (2003).

41. Bolliger, J. L., Belenguer, A. M. \& Nitschke, J. R. Enantiopure water-soluble Fe $4 L_{6}$ cages: Host-guest chemistry and catalytic activity. Angew. Chem. Int. Ed. 52, 79587962 (2013).

42. Grommet, A. B., Bolliger, J. L., Browne, C. \& Nitschke, J. R. A Triphasic sorting system: Coordination cages in ionic liquids. Angew. Chem. Int. Ed. 54, 15100-15104 (2015).

Acknowledgments: The authors thank Diamond Light Source (UK) for synchrotron beamtime on I19 (CY21497). This study was supported by the European Research Council (695009) and the UK Engineering and Physical Sciences Research Council (EPSRC, EP/P027067/1). B. N. N. T acknowledges Agency of Science, Technology and Research (A-STAR) for PhD funding. Author contributions: B. N. N. conducted the experiments, collected and processed data; J.D.T. developed the kinetic model and analysed the kinetic data; D.H. set up the quantitative ${ }^{1}$ H NMR experiments; A.B.G. and J.R.N conceived the idea; A.B.G. and J.L.B. conducted preliminary proof of concept experiments; T.K.R. and H.P.R. grew, collected and refined 
crystallographic data; J.R.N. resourced and supervised the studies; B.N.N. wrote the manuscript which was then proofread by all the authors.

Additional information: All data is available in the main text or the supplementary materials. CCDC 2047950 contains crystallographic data for cage 2 . These data can be obtained free of charge from The Cambridge Crystallographic Data Centre via www.ccdc.cam.ac.uk/structures.

Competing financial interests: Authors declare no competing financial interests. 